\title{
The effect of dexmedetomidine on motor-evoked potentials during pediatric posterior spinal fusion surgery: a retrospective case-control study
}

\section{Effet de la dexmédétomidine sur les potentiels évoqués moteurs pendant une chirurgie de fusion spinale postérieure chez l'enfant : une étude cas témoins rétrospective}

\author{
Francesca Holt, MB, BCh, BAO, FCAI 두 - Samuel Strantzas, MSc, DABNM • \\ Christian Zaarour, MD • Racha Chamlati, MD • Ian Vreugdenhil, BHSc • \\ Igor Luginbuehl, MD • Cengiz Karsli, MD • David Faraoni, MD, PhD, FAHA
}

Received: 21 October 2019/Revised: 18 April 2020/Accepted: 19 April 2020/Published online: 22 July 2020

(C) Canadian Anesthesiologists' Society 2020

\begin{abstract}
Purpose Motor-evoked potentials (MEPs) are frequently used in pediatric posterior spinal fusion surgery (PSFS) to detect spinal cord ischemia. Dexmedetomidine is increasingly being used as an adjunct to total intravenous anesthesia, but its effect on MEP amplitude has been variably reported. The purpose of this study was to evaluate the effect of an infusion of dexmedetomidine on the amplitude of MEPS.

Methods We performed a retrospective case-control study of 30 pediatric patients who received a $0.5 \mu \mathrm{g} \cdot \mathrm{kg}^{-1} \cdot \mathrm{hr}^{-1}$ infusion of dexmedetomidine, ten patients who received 0.3 $\mu \mathrm{g} \cdot \mathrm{kg}^{-1} \cdot \mathrm{hr}^{-1}$ dexmedetomidine, and 30 control patients who did not receive dexmedetomidine during PSFS. Two neurophysiologists reviewed the MEP amplitudes in six muscle groups at three time points: when the patient was turned prone (baseline; T1), one hour after incision (T2), and after exposure of the spine but before insertion of the first screw (T3).

Results In all muscles tested, the mean MEP amplitude was reduced by $T 3$ when dexmedetomidine was infused at
\end{abstract}

F. Holt, MB, BCh, BAO, FCAI $(\bowtie) \cdot$ C. Zaarour, MD .

R. Chamlati, MD · I. Luginbuehl, MD · C. Karsli, MD .

D. Faraoni, MD, PhD, FAHA

Department of Anesthesia and Pain Medicine, The Hospital for

Sick Children, University of Toronto, 555 University Avenue,

Toronto, ON M5G 1X8, Canada

S. Strantzas, MSc, DABNM - I. Vreugdenhil, BHSc Department of Surgical Neuromonitoring, The Hospital for Sick Children, University of Toronto, Toronto, ON, Canada
$0.5 \mu \mathrm{g} \cdot \mathrm{kg}^{-1} \cdot \mathrm{hr}^{-1}$. The greatest reduction from baseline MEP amplitude was $829 \mu \mathrm{V}$ (95\% confidence interval, 352 to 1230; $P<0.001)$ seen in first right dorsus interosseous. When dexmedetomidine was infused at $0.3 \mu \mathrm{g} \cdot \mathrm{kg}^{-1} \cdot \mathrm{hr}^{-1}$, there was a significant reduction in MEP amplitude in four of the six muscles tested at T3 compared with the control group.

Conclusions Dexmedetomidine at commonly used infusion rates of $0.3 \mu \mathrm{g} \cdot \mathrm{kg}^{-1} \cdot \mathrm{hr}^{-1}$ or $0.5 \mu \mathrm{g} \cdot \mathrm{kg}^{-1} \cdot \mathrm{hr}^{-1}$ causes a significant decrease in MEP amplitude during pediatric PSFS. We suggest that dexmedetomidine should be avoided in children undergoing PSFS so as not to confuse the interpretation of this important neurophysiological monitor.

\section{Résumé}

Objectif Les potentiels évoqués moteurs (PEM) sont fréquemment utilisés lors de chirurgies de fusion spinale postérieure chez l'enfant afin de détecter une ischémie de la moelle épinière. La dexmédétomidine est de plus en plus utilisée comme adjuvant à l'anesthésie intraveineuse totale, mais son effet sur l'amplitude des PEM n'a été rapporté que de façon variable. L'objectif de cette étude était d'évaluer l'effet d'une perfusion de dexmédétomidine sur l'amplitude des PEM.

Méthode Pendant une chirurgie de fusion spinale postérieure, nous avons réalisé une étude cas témoins rétrospective auprès de 30 patients pédiatriques ayant reçu une perfusion $0,5 \mu \mathrm{g} \cdot \mathrm{kg}^{-1} \cdot \mathrm{h}^{-1}$ de dexmédétomidine, 10 patients ayant reçu $0,3 \mu \mathrm{g} \cdot \mathrm{kg}^{-1} \cdot \mathrm{h}^{-1}$ de dexmédétomidine, et 30 patients témoins n'ayant pas reçu de 
dexmédétomidine. Deux neurophysiologistes ont passé en revue les amplitudes des PEM dans six groupes musculaires à trois moments de la chirurgie : lorsque le patient a été tourné sur le ventre (valeur de base; T1), une heure après l'incision (T2), et après l'exposition de la colonne mais avant l'insertion de la première vis (T3).

Résultats Dans tous les muscles testés, l'amplitude moyenne des PEM était réduite à T3 lorsque la dexmédétomidine était perfusée à $0,5 \mu \mathrm{g} \cdot \mathrm{kg}^{-1} \cdot \mathrm{h}^{-1}$. La plus grande réduction par rapport à l'amplitude de base des PEM était de $829 \mu \mathrm{V}$ (intervalle de confiance $95 \%$, 352 à 1230; $P<0,001)$ et a été observée au niveau du premier interosseux dorsal. Lorsque la dexmédétomidine était perfusée à $0,3 \mu \mathrm{g} \cdot \mathrm{kg}^{-1} \cdot \mathrm{h}^{-1}$, une réduction significative de l'amplitude des PEM a été observée dans quatre des six muscles testés à T3 par rapport au groupe témoin.

Conclusion La dexmédétomidine, administrée à des taux de perfusion fréquemment utilisés de $0,3 \mu \mathrm{g} \cdot \mathrm{kg}^{-1} \cdot \mathrm{h}^{-1}$ ou $0,5 \mu \mathrm{g} \cdot \mathrm{kg}^{-1} \cdot \mathrm{h}^{-1}$, a entrâné une réduction significative de l'amplitude des PEM pendant une chirurgie de fusion spinale postérieure chez l'enfant. Nous proposons d'éviter l'administration de dexmédétomidine chez les enfants devant subir une chirurgie de fusion spinale postérieure afin de ne pas brouiller l'interprétation de ce moniteur neurophysiologique important.

Keywords Dexmedetomidine · Evoked potentials · Neurophysiological monitoring · Spinal fusion .

Anesthesia intravenous

The incidence of new neurological damage (i.e., spinal cord injury) following posterior spinal fusion surgery (PSFS) in pediatric patients is reported to be $<2 \%$. ${ }^{1}$ There is strong evidence to suggest that neurophysiological monitoring is both sensitive and specific for detecting intraoperative neurological damage, so its use in this setting is recommended. ${ }^{2}$ Common neurophysiologic monitoring modalities include motor-evoked potentials (MEPs), somatosensory-evoked potentials (SSEPs), and raw electroencephalography (rEEG). Unlike the indirect afferent feedback signals received from SSEPs, MEPs directly monitor corticospinal motor tracts and are more sensitive than SSEPs to reduced blood flow resulting from vascular injury or hypotension. ${ }^{3}$ As a result of their increased sensitivity, changes in MEP amplitudes are detected prior to SSEP changes and can warn the surgeon and anesthesiologist of an impending problem, and therefore can be used to potentially reduce the risk of spinal cord injury.
Inhalational agents cause a dose-dependent reduction in MEPs and are arguably considered incompatible with effective neurophysiological monitoring. ${ }^{4}$ For this reason, total intravenous anesthesia (TIVA), using propofol and remifentanil, is commonly used in pediatric spinal fusion surgery. ${ }^{5}$ The highly selective $\alpha_{2}$-agonist, dexmedetomidine, is increasingly being used as an adjunct to propofol during TIVA. Its effect on MEPs during PSFS has been variably reported as both significantly attenuating the amplitude of MEPs or not adversely affecting MEP monitoring, depending on the individual study. ${ }^{6,7}$

In this retrospective case-control study, we sought to measure the effect of dexmedetomidine on MEPs during pediatric PSFS.

\section{Methods}

After research ethics board approval (27 December 2018; REB 1000062901) at The Hospital for Sick Children (Toronto, Canada), we retrospectively reviewed the medical records of 70 consecutive patients with idiopathic scoliosis who underwent posterior spinal surgery with instrumentation between 17 June 2013 and 10 May 2017. The study group included all patients having scoliosis surgery during this time period.

We included children and adolescents with idiopathic scoliosis aged between 7 and 18 years old who underwent posterior spine instrumentation. The same surgeon and the same anesthesiologist were involved in all the cases. Exclusion criteria included neuromuscular diseases or congenital scoliosis, growing rod distraction surgery, American Society of Anesthesiologists (ASA) physical status > III, opioid or ketamine use within three months prior to surgery, preoperative use of an antidepressant or anticonvulsant medications, and a body mass index $>40$ $\mathrm{kg} \cdot \mathrm{m}^{-1}$.

In this case series of 70 consecutive patients, 30 patients received dexmedetomidine at $0.5 \mu \mathrm{g} \cdot \mathrm{kg}^{-1} \cdot \mathrm{hr}^{-1}$ and the subsequent ten patients received dexmedetomidine at 0.3 $\mu \mathrm{g} \cdot \mathrm{kg}^{-1} \cdot \mathrm{hr}^{-1}$. The data from these patients was matched to the next 30 consecutive patients who did not receive dexmedetomidine and formed the control group.

All patients had intravenous induction with 3-4 $\mathrm{mg} \cdot \mathrm{kg}^{-1}$ propofol after which they received $0.1 \mathrm{mg} \cdot \mathrm{kg}^{-1}$ of morphine and $0.6 \mathrm{mg} \cdot \mathrm{kg}^{-1}$ of rocuronium. All patients also received $20 \mathrm{mg} \cdot \mathrm{kg}^{-1}$ tranexamic acid. Once intubated, infusions were started and the patient was turned prone. In the prone position, the neurophysiologist ensured that the muscle relaxation had dissipated by recording a train-offour from the left and right abductor hallucis ( $\mathrm{AH})$ muscles 
in the foot after stimulation of left and right posterior tibial nerves at the medial malleolus.

All patients were started on a propofol infusion at 166 $\mu \mathrm{g} \cdot \mathrm{kg}^{-1} \cdot \mathrm{min}^{-1}$, remifentanil $0.2 \mu \mathrm{g} \cdot \mathrm{kg}^{-1} \cdot \mathrm{min}^{-1}$, and tranexamic acid $10 \mathrm{mg} \cdot \mathrm{kg}^{-1} \cdot \mathrm{hr}^{-1}$. Patients in the treatment arm groups also received dexmedetomidine at 0.3 or $0.5 \mu \mathrm{g} \cdot \mathrm{kg}^{-1} \cdot \mathrm{hr}^{-1}$. Patients in the control group did not receive dexmedetomidine infusions. Once baseline neuromonitoring was established in the prone position, the propofol infusion was decreased to $100 \mu \mathrm{g} \cdot \mathrm{kg}^{-1} \cdot \mathrm{min}^{-1}$ in the dexmedetomidine group, while it was kept at 166 $\mu \mathrm{g} \cdot \mathrm{kg}^{-1} \cdot \mathrm{min}^{-1}$ in the control group. After this, the rEEG was used to titrate the depth of anesthesia by adjusting the propofol and remifentanil infusions alone, leaving the dexmedetomidine infusion unchanged. The rEEG was converted into a compressed spectral array using the Nicolet Endeavor $\mathrm{CR}^{\mathrm{TM}}$ (Middleton, USA). The compressed spectral array was maintained at a power ratio of $50 \%$ delta/theta to $50 \%$ alpha/beta. This ensured steady state anesthetic depth and, along with the use of TIVA, minimized any trial-to-trial MEP variability. All deviations from baseline infusions rates were recorded and analyzed.

Hemodynamic stability was ensured, monitored through the use of invasive blood pressure monitoring. The mean arterial pressure was maintained within the normal range at the discretion of the anesthesiologist, who adjusted infusion rates of propofol and remifentanil only, (not dexmedetomidine), whilst maintaining anesthetic depth.

After intubation, a pair of sub-dermal needle electrodes were placed in the left and right foot first dorsal interosseous, tibialis anterior (TA), and $\mathrm{AH}$ muscles by the neurophysiologist. Needle electrodes were inserted over the motor cortex $1 \mathrm{~cm}$ anterior to $\mathrm{C} 1-\mathrm{C} 2$, to deliver a transcranial electrical stimulus, thus completing the 10-20 measurement system. ${ }^{8}$ The three muscle groups studied were the left and right dorsal interosseous (DI), TA, and AH muscles. The time points for recording MEPs were at baseline once the patient was prone (T1), one hour after surgical incision (T2), and once exposure of the spine was complete and prior to spinal instrumentation (T3).

The MEP peak-to-peak amplitudes were acquired (using Nicolet Endeavor CR) by delivering a train of five, 50$\mu \mathrm{sec}$, constant voltage, anodal pulses with a 1.1 -msec interstimulus interval $(909 \mathrm{~Hz})$, alternating over each hemisphere. Stimulus intensity ranged from 250 to 500 volts and was increased in a stepwise manner until maximum amplitude responses were obtained from each of the muscle groups. Motor-evoked potential amplitudes were recorded using a 30-1500 Hertz filter and displayed across a 100-msec window with a $200 \mu \mathrm{V}$ screen sensitivity.
One neurophysiologist retrospectively measured and documented the maximum amplitude of the MEPs from each of the three muscle groups at three distinct time points and a second neurophysiologist checked the measurements for accuracy. Measurements were made after all patient identifiers were removed, leaving only a timeline of the stacked MEPs acquired throughout each case, blinding the neurophysiologists to patient identity and treatment arm.

The primary outcome was reduction in MEP amplitude by time T3 compared with baseline amplitude. Consensus guidelines recommend a decrease in signal amplitude $>$ $60 \%$ as a "significant warning criteria" in spinal fusion surgery; however, there is institutional and trial-to-trial variability in what is considered an "alert signal". ${ }^{9}$ In keeping with our institutional practice of an alert at 50\% loss of signal compared with baseline, the secondary outcome was a clinically significant reduction in amplitude compared with baseline, based on the 50\% threshold alarm criteria. This alert criterion was used prior to any data collection or analysis.

Two investigators recorded the rates of propofol, remifentanil, and dexmedetomidine at the three time points. Patient characteristics including ASA physical status, weight, age, and sex were also recorded.

\section{Statistical analysis}

Categorical variables are expressed as number and percentage $(\%)$, and continuous variables are expressed as median [interquartile range (IQR)] or mean (standard deviation $[\mathrm{SD}])$. Statistical analysis was performed by twoway analysis of variance for repeated measures, testing for a difference between the groups, a difference between values at various times, and for a time $\mathrm{x}$ group interaction. All $P$ values are two-sided, and an $\alpha$ level of 0.05 was considered statistically significant. The statistical software STATA 15.1 (Stata Corp, College Station, TX, USA) was used for all analyses.

\section{Results}

Fifty-four patients received a dexmedetomidine infusion during the time period of our study. Fourteen patients were excluded because of congenital scoliosis or because they underwent growing rod distraction surgery. This left 40 patients in the treatment group, of which 30 received dexmedetomidine at $0.5 \mu \mathrm{g} \cdot \mathrm{kg}^{-1} \cdot \mathrm{hr}^{-1}$ and ten received dexmedetomidine at $0.3 \mu \mathrm{g} \cdot \mathrm{kg}^{-1} \cdot \mathrm{hr}^{-1}$. There were 30 patients in the control group who did not receive dexmedetomidine. Demographic characteristics of the three groups are reported in Table 1. 
Table 1 Subject demographics

\begin{tabular}{llll}
\hline Variables & $\begin{array}{l}\text { Controls } \\
(n=30)\end{array}$ & $\begin{array}{l}\text { Dexmedetomidine } \\
0.3 \mu \mathrm{g} \cdot \mathrm{kg}^{-1} \cdot \mathrm{hr}^{-1}(n=10)\end{array}$ & $\begin{array}{l}\text { Dexmedetomidine } \\
0.5 \mu \mathrm{g} \cdot \mathrm{kg}^{-1} \cdot \mathrm{hr}^{-1}(n=30)\end{array}$ \\
\hline Age, yr & $15.0[14-16]$ & $14.5[13-16]$ & $15.0[14-16]$ \\
Weight & $57.0[42.8-63.7]$ & $52.4[50.7-58.8]$ & $52.5[47.5-58.2]$ \\
Female & $25(83 \%)$ & $9(90 \%)$ & $25(83 \%)$ \\
ASA-I & $16(53 \%)$ & $3(30 \%)$ & $20(67 \%)$ \\
ASA-II & $13(43 \%)$ & $4(40 \%)$ & $10(33 \%)$ \\
ASA-III & $1(3 \%)$ & $3(30 \%)$ & 0
\end{tabular}

Categorical data are presented as number (\%). Continuous data are presented as median [interquartile range].

ASA = American Society of Anesthesiologists physical status classification score.

The median [IQR] time interval from baseline to T3 was comparable between the groups at 144 [144-151] min for the control group, 155 [126-163] $\mathrm{min}$ for the 0.5 $\mu \mathrm{g} \cdot \mathrm{kg}^{-1} \cdot \mathrm{hr}^{-1}$ dexmedetomidine group, and $155[126-$ 206] $\mathrm{min}$ for the $0.3 \mu \mathrm{g} \cdot \mathrm{kg}^{-1} \cdot \mathrm{hr}^{-1}$ group.

The mean (SD) propofol and remifentanil rates were similar between groups, with the rates of propofol at T2 being 165 (14), $114(20)$, and 133 (24) $\mu \mathrm{g} \cdot \mathrm{kg}^{-1} \cdot \mathrm{min}^{-1}$ for control, 0.3, and 0.5 groups respectively. Mean (SD) propofol rates at T3 were 158 (20), 120 (23), and 106 (22) $\mu \mathrm{g} \cdot \mathrm{kg}^{-1} \cdot \mathrm{min}^{-1}$ for the control, 0.3 , and 0.5 groups respectively. Mean (SD) remifentanil rates at $\mathrm{T} 2$ were 0.36 (0.11), $0.37(0.11)$, and $0.37(0.11) \mu \mathrm{g} \cdot \mathrm{kg}^{-1} \cdot \mathrm{min}^{-1}$ for the control, 0.3 , and 0.5 groups respectively. Mean (SD) remifentanil rates at T3 were 0.34 (0.11), $0.31(0.09)$, and $0.35(0.09) \mu \mathrm{g} \cdot \mathrm{kg}^{-1} \cdot \mathrm{min}^{-1}$ for the control, 0.3 , and 0.5 groups respectively.

The amplitude of the MEPs was recorded for each muscle group at each time point, for each study group (Table 2). We also determined the percentage reduction in MEP amplitude from baseline to T3.

In all muscles tested, the mean MEP amplitude was reduced by T3 when dexmedetomidine was infused at 0.5 $\mu \mathrm{g} \cdot \mathrm{kg}^{-1} \cdot \mathrm{hr}^{-1}$ (all $P \leq 0.002$ when comparing 0.5 $\mu \mathrm{g} \cdot \mathrm{kg}^{-1} \cdot \mathrm{hr}^{-1}$ at T3 with the control group at T3). When dexmedetomidine was infused at $0.5 \mu \mathrm{g} \cdot \mathrm{kg}^{-1} \cdot \mathrm{hr}^{-1}$, a significant difference compared with control was also observed by $\mathrm{T} 2$ in the TA and $\mathrm{AH}$ muscles bilaterally. In the left TA muscle, by T2 the mean MEP in the 0.5 group was reduced by $194.5 \mu \mathrm{V}$ (a $61 \%$ reduction) compared with control $(95 \%$ confidence interval [CI], 166 to $632 ; P$ $<0.001)$. In the right $\mathrm{TA}$, when dexmedetomidine was infused at $0.5 \mu \mathrm{g} \cdot \mathrm{kg}^{-1} \cdot \mathrm{hr}^{-1}$, the mean MEP amplitude had reduced by $149 \mu \mathrm{V}$ by T2 compared with control, (95\% CI, 248 to $718 ; P<0.001)$. This is a $53 \%$ reduction compared with control.
When dexmedetomidine was infused at 0.3 $\mu \mathrm{g} \cdot \mathrm{kg}^{-1} \cdot \mathrm{hr}^{-1}$, there was a significant reduction in amplitude compared with the control group by T3 in four of the six muscles tested. There was no significant reduction compared with control in any muscle group by T2 when dexmedetomidine was infused at 0.3 $\mu \mathrm{g} \cdot \mathrm{kg}^{-1} \cdot \mathrm{hr}^{-1}$ (Table 2).

By the time the spine was exposed, we found that MEP amplitude had fallen by a clinically significant level (i.e., $50 \%$ reduction from baseline in our institution) in four of six tested muscles $(67 \%)$ when dexmedetomidine was infused at $0.5 \mu \mathrm{g} \cdot \mathrm{kg}^{-1} \cdot \mathrm{hr}^{-1}$. When dexmedetomidine was infused at $0.3 \mu \mathrm{g} \cdot \mathrm{kg}^{-1} \cdot \mathrm{hr}^{-1}$, the alarm threshold criterion was met in the DI muscles bilaterally and in the left $\mathrm{AH}$ muscle.

\section{Discussion}

Our study found that dexmedetomidine infused at commonly used doses of $0.5 \mu \mathrm{g} \cdot \mathrm{kg}^{-1} \cdot \mathrm{hr}^{-1}$ and 0.3 $\mu \mathrm{g} \cdot \mathrm{kg}^{-1} \cdot \mathrm{hr}^{-1}$ significantly reduced MEP amplitude compared with control, prior to instrumentation of the spine, in both upper and lower muscle groups tested. The results translate clinically because alarm criteria (i.e., MEP amplitude decrease of $50 \%$ or more, in our institution) was met in four of the six muscles tested, reducing reliability of MEP monitoring in this setting.

The highly selective $\alpha_{2}$ agonist, dexmedetomidine, has sedative, analgesic, and propofol-sparing effects, and is therefore increasingly being used as an adjunct to propofolbased TIVA. ${ }^{10}$ It is also advantageous in reducing rates of delirium and agitation and for its cardiovascular stabilising properties. ${ }^{11}$

Motor-evoked potentials are monitored during PSFS to provide feedback signals and guide surgical response and therefore reduce the rate of neurological damage. Indeed, 
Table 2 Motor-evoked potential amplitude for each muscle group at each time point

\begin{tabular}{|c|c|c|c|c|c|c|c|c|}
\hline Muscle & Time & $\begin{array}{l}\text { Control group }(n= \\
30)\end{array}$ & $\begin{array}{l}\text { Dexmedetomidine } \\
0.3 \mu \mathrm{g} \cdot \mathrm{kg}^{-1} \cdot \mathrm{hr}^{-1}(n= \\
\quad 10)\end{array}$ & $95 \% \mathrm{CI}$ & $\begin{array}{l}P \\
\text { value }\end{array}$ & $\begin{array}{l}\text { Dexmedetomidine } \\
0.5 \mu \mathrm{g} \cdot \mathrm{kg}^{-1} \cdot \mathrm{hr}^{-1}(n= \\
\quad 30)\end{array}$ & $95 \% \mathrm{CI}$ & $\begin{array}{l}P \\
\text { value }\end{array}$ \\
\hline \multirow[t]{6}{*}{$1^{\mathrm{ST}}$ DI LEFT } & \multirow[t]{2}{*}{ Baseline } & 900 & 430 & & & 835 & & \\
\hline & & [357-1469] & [318-819] & & & [434-1370] & & \\
\hline & \multirow[t]{2}{*}{$\mathrm{T} 2$} & 818 & 402 & \multirow[t]{2}{*}{-67 to 934} & \multirow[t]{2}{*}{0.09} & 592 & \multirow{2}{*}{$\begin{array}{c}-163 \text { to } \\
577\end{array}$} & \multirow[t]{2}{*}{0.09} \\
\hline & & [357-1500] & [238-779] & & & [222-1000] & & \\
\hline & \multirow[t]{2}{*}{$\mathrm{T} 3$} & 800 & $* 189$ & \multirow[t]{2}{*}{260 to 1415} & \multirow[t]{2}{*}{$<0.001$} & $* 183$ & \multirow[t]{2}{*}{364 to 1024} & \multirow[t]{2}{*}{$<0.001$} \\
\hline & & [500-1500] & [78-255] & & & [63-360] & & \\
\hline \multicolumn{2}{|c|}{$\begin{array}{l}\% \text { reduction baseline to } \\
\mathrm{T} 3\end{array}$} & $11 \%$ & $* 56 \%$ & & & $* 78 \%$ & & \\
\hline \multirow{6}{*}{$\begin{array}{l}1^{\mathrm{ST}} \mathrm{DI} \\
\text { RIGHT }\end{array}$} & \multirow[t]{2}{*}{ Baseline } & 989 & 681 & & & 975 & & \\
\hline & & [500-1500] & [445-1254] & & & [438-1945] & & \\
\hline & \multirow[t]{2}{*}{$\mathrm{T} 2$} & 1050 & 627 & \multirow{2}{*}{$\begin{array}{l}-201 \text { to } \\
1199\end{array}$} & \multirow[t]{2}{*}{0.20} & 525 & \multirow{2}{*}{$\begin{array}{c}-224 \text { to } \\
827\end{array}$} & \multirow[t]{2}{*}{0.09} \\
\hline & & [504-1624] & [258-1120] & & & [244-1507] & & \\
\hline & \multirow[t]{2}{*}{$\mathrm{T} 3$} & 1015 & $* 126$ & \multirow[t]{2}{*}{364 to 1350} & \multirow[t]{2}{*}{0.003} & $* 186$ & \multirow[t]{2}{*}{352 to 1300} & $<0.001$ \\
\hline & & [500-1800] & [77-368] & & & [54-750] & & \\
\hline $\begin{array}{l}\% \text { reduction } b \\
\text { T3 }\end{array}$ & aseline to & NA & $* 82 \%$ & & & $* 81 \%$ & & \\
\hline TA LEFT & Baseline & 412 & 243 & & & 314 & & \\
\hline & & [293-600] & [156-326] & & & {$[160-546]$} & & \\
\hline & $\mathrm{T} 2$ & 519 & 217 & 166 to 632 & 0.01 & $* 183$ & 165 to 632 & $<0.001$ \\
\hline & & [337-916] & [108-433] & & & [97-359] & & \\
\hline & $\mathrm{T} 3$ & 650 & $* 166$ & 202 to 941 & $<0.001$ & $* 179$ & 303 to 794 & $<0.001$ \\
\hline & & [435-1000] & [889-330] & & & [51-339] & & \\
\hline $\begin{array}{l}\% \text { reduction } \mathrm{b} \\
\mathrm{T} 3\end{array}$ & aseline to & NA & $32 \%$ & & & $32 \%$ & & \\
\hline TA RIGHT & Baseline & 514 & 218 & & & 256 & & \\
\hline & & [221-770] & [161-723] & & & [160-447] & & \\
\hline & $\mathrm{T} 2$ & 598 & 244 & -49 to 785 & 0.04 & $* 199$ & 248 to 719 & 0.04 \\
\hline & & [290-900] & [137-399] & & & [116-300] & & \\
\hline & $\mathrm{T} 3$ & 665 & 262 & 5 to 885 & 0.02 & $* 174$ & 238 to 743 & $<0.001$ \\
\hline & & [250-1099] & [98-601] & & & [86-253] & & \\
\hline $\begin{array}{l}\% \text { reduction } \mathrm{b} \\
\mathrm{T} 3\end{array}$ & aseline to & NA & NA & & & $32 \%$ & & \\
\hline AH LEFT & Baseline & 229 & 304 & & & 227 & & \\
\hline & & [173-407] & [143-417] & & & [99-389] & & \\
\hline & $\mathrm{T} 2$ & 318 & 229 & -6 to 329 & 0.15 & $* 123$ & 80 to 334 & $<0.001$ \\
\hline & & [225-500] & [93-443] & & & [58-233] & & \\
\hline & $\mathrm{T} 3$ & 400 & $* 124$ & 75 to 661 & 0.008 & $* 50$ & 228 to 578 & $<0.001$ \\
\hline & & [300-715] & [80-188] & & & [22-239] & & \\
\hline $\begin{array}{l}\% \text { reduction } \mathrm{b} \\
\mathrm{T} 3\end{array}$ & aseline to & NA & $* 60 \%$ & & & $78 * \%$ & & \\
\hline AH RIGHT & Baseline & 296 & 244 & & & 197 & & \\
\hline & & {$[175-500]$} & {$[161-522]$} & & & [106-450] & & \\
\hline & $\mathrm{T} 2$ & 283 & 190 & -91 to 309 & 0.22 & $* 134$ & 59 to 307 & 0.003 \\
\hline & & [158-600] & [68-317] & & & [79-277] & & \\
\hline & $\mathrm{T} 3$ & 391 & 184 & 20 to 623 & 0.02 & $* 69$ & 205 to 557 & $<0.001$ \\
\hline & & [173-700] & [28-254] & & & [32-168] & & \\
\hline
\end{tabular}


Table 2 continued

\begin{tabular}{|c|c|c|c|c|c|c|c|}
\hline Muscle & $\begin{array}{l}\text { Control group }(n= \\
30)\end{array}$ & $\begin{array}{l}\text { Dexmedetomidine } 0.3 \\
\mu \mathrm{g} \cdot \mathrm{kg}^{-1} \cdot \mathrm{hr}^{-1}(n=10)\end{array}$ & $95 \% \mathrm{CI}$ & $\begin{array}{l}P \\
\text { value }\end{array}$ & $\begin{array}{l}\text { Dexmedetomidine } 0.5 \\
\mu \mathrm{g} \cdot \mathrm{kg}^{-1} \cdot \mathrm{hr}^{-1}(n=30)\end{array}$ & $95 \% \mathrm{CI}$ & $\begin{array}{l}P \\
\text { value }\end{array}$ \\
\hline $\begin{array}{l}\% \text { reduction baseline to } \\
\text { T3 }\end{array}$ & NA & $24 \%$ & & & $65 \%$ & & \\
\hline
\end{tabular}

The motor-evoked potential amplitudes are displayed in $\mu \mathrm{V}$. Data are presented as median [interquartile range].

*Denotes $P<0.005$ compared with control group. AH = abductor hallucis; $95 \% \mathrm{CI}=95 \%$ confidence interval for the true difference between the control group and dexmedetomidine amplitude; $\mathrm{DI}=$ dorsal interosseous; $\mathrm{TA}=$ tibialis anterior; $\mathrm{T} 2=$ one hour post incision; $\mathrm{T} 3=$ immediately prior to spinal instrumentation.

since the introduction of routine MEP monitoring, there has been a decrease in both permanent and new neurological injury deficits following spinal fusion surgery. ${ }^{9}$ Therefore, drugs that alter the reliability of MEP monitoring alter the reliability of these important safety tests.

There are few reports in the literature pertaining to the safety of dexmedetomidine in this setting and their conclusions differ. ${ }^{6,12}$ The results of our study confirm the results of a smaller study by Mahmoud et al., which suggests that dexmedetomidine may attenuate the amplitude of MEPs at clinically relevant target concentrations during PSFS. ${ }^{12}$

The study by Mahmoud et al., ${ }^{12}$ had a factorial design and used varying concentrations of dexmedetomidine and propofol targeted to plasma levels. The primary outcome was the amplitude of transcranial MEPs. The authors found that increasing doses of dexmedetomidine, used as an adjunct to propofol anesthesia in 40 patients aged $10-25 \mathrm{yr}$, significantly attenuated transcranial evoked motor potentials. They considered a significant decrease to be a $75 \%$ reduction from baseline, a slightly larger decrease to our own alarm criteria (50\%). A total of 23 of 40 patients had significant attenuation of MEP amplitude for one or more muscles. Similar to our own study, baseline transcranial evoked potentials were measured prior to commencement of dexmedetomidine at three different target concentrations. In the study by Mahmoud et al., targeted blood levels were achieved using loading doses $\left(0.4,0.6\right.$, and $\left.0.8 \mathrm{ng} \cdot \mathrm{mL}^{-1}\right)$ with the Petroz and Marsh compartment models ${ }^{13,14}$ rather than constant infusion rates, so equivalence is challenging. Patients were randomized to one of five dose combinations of dexmedetomidine with propofol. The lower concentration used in Mahmoud's study was $0.4 \mathrm{ng} \cdot \mathrm{mL}^{-1}$ with 2.5 $\mu \mathrm{g} \cdot \mathrm{mL}^{-1}$ propofol target controlled infusion (consistent with moderate sedation ${ }^{15}$ and light anesthesia, ${ }^{14}$ respectively). The authors state that these low concentrations of dexmedetomidine and propofol, did not significantly attenuate MEPs $(n=7)$, but doses of dexmedetomidine above this concentration attenuated MEPs in an unacceptable percentage of patients. Only the loading phase data were analyzed as 17 patients had significantly reduced MEPs. We did not use loading doses, but we found both statistical and clinically significant decreases in MEP amplitude, despite absence of the loading dose. Acquisition of MEPs was similar to our own protocol, using scalp and peripheral responses, recording from TA and first DI (we also reviewed $\mathrm{AH}$ ), and using similar stimulating techniques with the International 10-20 system.

In a small retrospective review of prospectively collected data in nine adolescent patients, Tobias et al. ${ }^{6}$ administered a bolus dose of $1 \mu \mathrm{g} \cdot \mathrm{kg}^{-1}$ of dexmedetomidine at the end of spinal fusion surgery, followed by an infusion at $0.5 \mu \mathrm{g} \cdot \mathrm{kg}^{-1} \cdot \mathrm{hr}^{-1}$ for $24 \mathrm{hr}$ postoperatively. There was a reduction in amplitude in MEPs after the loading dose in one patient but no change in SSEPs. In this patient, the bispectral index (BIS) decreased from 58 to 31 . To compensate for this, in the remaining eight patients, the propofol infusion rate was altered to maintain the starting BIS. In our study, the propofol infusion rate started at $166 \mu \mathrm{g} \cdot \mathrm{kg}^{-1} \cdot \mathrm{min}^{-1}$ compared with $100 \mu \mathrm{g} \cdot \mathrm{kg}^{-1} \cdot \mathrm{min}^{-1}$ in the Tobias study, with both studies starting remifentanil at $0.2 \mu \mathrm{g} \cdot \mathrm{kg}^{-1} \cdot \mathrm{min}^{-1}$, altering remifentanil dosing to maintain normal mean arterial pressure and anesthetic depth ranges. In the Tobias study, at the conclusion of the surgical procedure, the BIS was maintained at $49 \pm 4$ by reducing propofol infusion rates to $78 \pm 14 \mu \mathrm{g} \cdot \mathrm{kg}^{-1} \cdot \mathrm{min}^{-1}$. We performed our investigations during spinal exposure. We question whether surgical stimulation at such a low propofol infusion rate would raise the BIS and therefore question the clinical applicability of their conclusion that downward adjustment of propofol with a dexmedetomidine infusion rate of $0.5 \mu \mathrm{g} \cdot \mathrm{kg}^{-1} \cdot \mathrm{hr}^{-1}$ does not adversely affect SSEP or MEP monitoring.

The Tobias et al. study reported no statistically significant difference in MEP or SSEPs observed before or after administration of the dexmedetomidine loading 
dose once propofol was adjusted for BIS, although one additional patient had an abnormal response secondary to a brachial plexus injury. The MEP was only measured before and at completion of the loading dose (over $20 \mathrm{~min}$ ), with no cited time point in minutes. This, coupled with the smaller number of patients investigated, may account for the difference in outcome compared with our own study.

Our study's retrospective design, from a single institution, does present some limitations. Although our study is one of the largest published, it remains a relatively small cohort that is susceptible to selection bias, particularly by a single operator. Our data collection was thorough, with minimal missing data encountered, and with similar group sizes (although not identical). We retrospectively blinded the neurophysiologists to treatment arm group in a further attempt to prevent bias and although it is unlikely, it remains possible that the neurophysiologist could associate a trace with an individual case.

It is reported that new neurological weakness during PSFS is unlikely to occur if no deterioration in MEP amplitude is observed. ${ }^{16}$ In the control group (those who received only propofol and remifentanil infusions), no appreciable deterioration in signal occurred. Nevertheless, the signal deteriorated with dexmedetomidine infusions at both rates.

The use of a propofol infusion could be considered a confounding factor that attenuates MEP amplitudes over time-this phenomenon is referred to as "anesthetic fade". ${ }^{17}$ This was avoided through the use of raw and compressed electroencephalogram (EEG) maintaining a steady state anesthesia, as described above. Mean propofol rates were higher at $\mathrm{T} 2$ compared with $\mathrm{T} 3$ and lower with the addition of dexmedetomidine.

It is noteworthy to observe that the duration of MEP loss may be a better predictor of neurologic outcome than the scale of MEP change, particularly when MEP loss is greater than $40-60$ minutes. ${ }^{18}$ We reviewed three distinct time points and review of continuous data may benefit future studies, although we did measure MEP amplitudes at comparable time points amongst groups. We did not administer or test the effect of bolus dosing on MEP amplitude however cumulative dosing can be extrapolated from our data. Target control infusion pumps used to achieve specific predicted target blood drug concentrations would more accurately reflect plasma concentrations, since the drug follows linear pharmacokinetics during an infusion. ${ }^{10}$

Although normal hemodynamic and anesthetic depth range was maintained, we did not analyze compressed EEG and hemodynamic data for each specific time point. This limits the degree of confidence that the results reported are solely due to dexmedetomidine administration and not confounded by subtle differences in either parameter. On the other hand, statistically and clinically significant differences were observed between the groups. The most significant change was the presence or absence of dexmedetomidine and not significant hemodynamic or EEG change, with any hemodynamic or EEG change existing within the normal range.

As seen in Table $1,30 \%$ of patients in the low dose dexmedetomidine group were ASA physical status III $v s$ $3 \%$ of controls and $0 \%$ of the higher dose dexmedetomidine group. The low dose dexmedetomidine group was the smallest group. Although unlikely, as morbidity should not effect change in MEP amplitude, confounding may be present due to differences in patient background history. The most significant change in MEP amplitude was seen between the control vs higher dose group, and these groups had similar ASA physical status.

In conclusion, dexmedetomidine at commonly used infusion rates of $0.3 \mu \mathrm{g} \cdot \mathrm{kg}^{-1} \cdot \mathrm{hr}^{-1}$ or $0.5 \mu \mathrm{g} \cdot \mathrm{kg}^{-1} \cdot \mathrm{hr}^{-1}$ caused a significant decrease in the amplitude of MEPs during PSFS. Based on the results of our study, we suggest that the use of dexmedetomidine in children undergoing PSFS should be assessed in a prospective randomizedcontrolled trial; however, the findings from this present study would make this ethically challenging.

Author contributions Francesca Holt, Sam Stranzas, Christian Zaarour, Ian Vreugdenhil, and David Faraoni contributed to all aspects of this manuscript, including study conception and design; acquisition, analysis, and interpretation of data; and drafting the article. Racha Chamlati contributed to acquisition of data and drafting the article. Igor Luginbuehl and Cengiz Karsli contributed to drafting the article.

Disclosures None.

Funding statement None.

Editorial responsibility This submission was handled by Dr. Hilary P. Grocott, Editor-in-Chief, Canadian Journal of Anesthesia.

\section{References}

1. Reames DL, Smith JS, Fu K-MG, et al. Complications in the surgical treatment of 19,360 cases of pediatric scoliosis. Spine (Phila Pa 1976) 2011; 36: 1484-91.

2. Fehlings $M G$, Brodke DS, Norvell DC, Dettori JR. The evidence for intraoperative neurophysiological monitoring in spine surgery. Spine (Phila Pa 1976) 2010; 35(9 Suppl): S37-46.

3. Schwartz DM, Auerbach JD, Dormans JP, et al. Neurophysiological detection of impending spinal cord injury during scoliosis surgery. J Bone Joint Surg Am 2007; 89: 2440-9.

4. Raw DA, Beattie JK, Hunter JM. Anaesthesia for spinal surgery in adults. Br J Anaesth 2003; 91: 886-904.

5. Samra SK, Dy EA, Welch KB, Lovely LK, Graziano GP. Remifentanil- and fentanyl-based anesthesia for intraoperative 
monitoring of somatosensory evoked potentials. Anesth Analg 2001; 92: 1510-5.

6. Tobias JD, Goble TJ, Bates G, Anderson JT, Hoernschemeyer $D G$. Effects of dexmedetomidine on intraoperative motor and somatosensory evoked potential monitoring during spinal surgery in adolescents. Paediatr Anaesth 2008; 18: 1082-8.

7. Brennen K, König M, Mahmoud M. Use of dexmedetomidine and ketamine infusions during scoliosis repair surgery with somatosensory and motor-evoked potential monitoring: a case report. AANA J 2011; 79: 89-90.

8. Klem GH, Lüders HO, Jasper HH, Elger C. The ten-twenty electrode system of the International Federation. The International Federation of Clinical Neurophysiology. Electroencephalogr Clin Neurophysiol Suppl 1999; 52: 3-6.

9. Vitale MG, Skaggs DL, Pace GI, et al. Best practices in intraoperative neuromonitoring in spine deformity surgery: development of an intraoperative checklist to optimize response. Spine Deform 2014; 2: 333-9.

10. Tobias JD. Dexmedetomidine: applications in pediatric critical care and pediatric anesthesiology. Pediatr Crit Care Med 2007; 8: 115-31.

11. Kaur M, Singh PM. Current role of dexmedetomidine in clinical anesthesia and intensive care. Anesth Essays Res 2011; 5: 12833.

12. Mahmoud M, Sadhasivam S, Salisbury $S$, et al. Susceptibility of transcranial electric motor-evoked potentials to varying targeted blood levels of dexmedetomidine during spine surgery. Anesthesiology 2010; 112: 1364-73.
13. Petroz GC, Sikich $N$, James $M$, et al. A phase I, two-center study of the pharmacokinetics and pharmacodynamics of dexmedetomidine in children. Anesthesiology 2006; 105: 1098110 .

14. Marsh B, White M, Morton N, Kenny GN. Pharmacokinetic model driven infusion of propofol in children. Br J Anaesth 1991; 67: 41-8.

15. Colin PJ, Hannivoort LN, Eleveld DJ, et al. Dexmedetomidine pharmacokinetic-pharmacodynamic modelling in healthy volunteers: 1. Influence of arousal on bispectral index and sedation. Br J Anaesth 2017; 119: 200-10.

16. Macdonald DB, Skinner S, Shils J, Yingling C. Intraoperative motor evoked potential monitoring - a position statement by the American Society of Neurophysiological Monitoring. Clin Neurophysiol 2013; 124: 2291-316.

17. Lyon R, Feiner J, Lieberman JA. Progressive suppression of motor evoked potentials during general anesthesia: the phenomenon of "anesthetic fade". J Neurosurg Anesthesiol 2005; 17: 13-9.

18. Legatt AD, Emerson RG, Epstein CM, et al. ACNS Guideline: transcranial electrical stimulation motor evoked potential monitoring. J Clin Neurophysiol 2016; 33: 42-50.

Publisher's Note Springer Nature remains neutral with regard to jurisdictional claims in published maps and institutional affiliations. 